\title{
Characterization of novel dual tandem CD19/BCMA chimeric antigen receptor T cells to potentially treat multiple myeloma
}

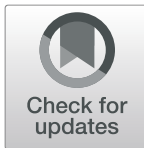

Liqing Kang ${ }^{1}$, Jian Zhang ${ }^{2,3}$, Minghao Li ${ }^{1}$, Nan Xu', Wei Qi ${ }^{1}$, Jingwen Tan ${ }^{1}$, Xiaoyan Lou', Zhou Yu ${ }^{4}$, Juanjuan Sun ${ }^{4}$, Zhenkun Wang ${ }^{5}$, Chengcheng Fu' ${ }^{2,3}$, Xiaowen Tang ${ }^{2,3}$, Haiping Dai ${ }^{2,3}$, Jia Chen ${ }^{2,3}$, Depei Wu ${ }^{2,3^{*}}$ and Lei Yu ${ }^{1,4^{*}}$ (D)

\begin{abstract}
Background: Treatment with chimeric antigen receptor (CAR)-engineered T cells directed against the B-cell maturation antigen (BCMA) promoted transient recovery from multiple myeloma (MM). However, the absence of this antigen on immature plasma cells may limit the efficacy of this modality and facilitate relapse. The purpose of this study is to characterize a novel CAR that includes both a single-chain variable fragment (scFv)-BCMA and an sCFv-CD19 in tandem orientation (tan-CAR) in an attempt to target both BCMA and CD19 expression on MM cells.

Method: The sCFv sequences from the anti-CD19 antibody FMC63 and the anti-BCMA antibody C11D5.3 were ligated in tandem with transmembrane and T-cell signaling domains to generate the tan-CAR construct. Specificity and efficacy of activated tan-CAR T cells were analyzed using in vitro proliferation, cytokine release, and cytolysis assays. We also evaluated the in vivo efficacy with a xenograft mouse model that included target tumor cells that expressed CD19 or BCMA and compared the results to those obtained with conventional CAR T cells.

Results: The in vitro studies revealed specific activation of tan-CAR T cells by K562 cells that overexpressed CD19 and/or BCMA. Cell proliferation, cytokine release, and cytolytic activity were all comparable to the responses of single scFv CAR T cells. Importantly, in vivo studies of tan-CAR T cells revealed specific inhibition of tumor growth in the mouse xenograft model that included cells expressing both CD19 and BCMA. Systemic administration of tanCAR T cells resulted in complete tumor remission, in contrast to the reduced efficacies of BCMA-CAR T and CD19CAR T alone in this setting.

Conclusion: We report the successful design and execution of novel tan-CAR T cells that promote significant antitumor efficacy against both CD19 and BCMA antigen-positive tumor cells in vitro and in vivo. The data from this study reveal a novel strategy that may help to reduce the rate of relapse in the treatment with single scFv-CAR T cells.
\end{abstract}

Keywords: Tandem-CAR T, Multiple myeloma, CD19, BCMA, Relapse

\footnotetext{
*Correspondence: wudepei@suda.edu.cn; ylyh188@163.com

${ }^{2}$ National Clinical Research Center for Hematologic Diseases, Jiangsu Institute

of Hematology, The First Affiliated Hospital of Soochow University, Suzhou,

China

${ }^{1}$ Institute of Biomedical Engineering and Technology, Shanghai Engineering Research Center of Molecular Therapeutics and New Drug Development,

School of Chemistry and Molecular Engineering, East China Normal University, NO, 3663 North Zhongshan Road, Shanghai 200065, China

Full list of author information is available at the end of the article
} 


\section{Introduction}

Multiple myeloma (MM) is a malignant neoplasm in which uncontrolled expansion and proliferation of clonal plasma cells leads to osteolytic lesions and bone marrow failure in association with end-organ damage [1]. Several new drugs and drug regimens have recently been introduced in an effort to improve treatment for MM. Although these regimens are overall safer than previous therapies, only a limited number patients respond completely and effectively [2-4]. As such, we need to consider more innovative strategies with the aim of generating a more significant and long-lasting therapeutic effect.

Cellular immunotherapy is a novel and evolving treatment strategy in which cytotoxic $\mathrm{T}$ cells are engineered to promote recognition of specific tumor antigens. Adoptive transfer of chimeric antigen receptor (CAR)-engineered autologous $\mathrm{T}$ cells has met with unprecedented success for the treatment of hematological malignancies [5-7]. In parallel, several diverse immunotherapeutic approaches currently under investigation have utilized this approach and focus on engineering target antigen specificity and $\mathrm{T}$ cell activation [8]. The CAR T-cell approach for the treatment of MM has shown considerable promise and has been associated with manageable toxicities. Notably, several efforts have focused on B-cell maturation antigen (BCMA) due to its preferential expression on plasma cells [9-11]. To date, early phase clinical trials that explore the impact of single-chain fragment variable (scFv) antiBCMA-modified CAR T cells have shown undeniably high response rates. Unfortunately, the responses are often transient with frequent relapse [12]. One of the reasons of relapse might due to a group of residual malignant CD19 ${ }^{+}$ plasma cells which can be detected among the tumor cells; these cells can drive self-renewal, myeloma propagation, and resistance to chemotherapy and can be considered to be cancer stem cells [13]. Furthermore, sustained remission was observed with advanced MM in one patient who received anti-CD19 CAR $\mathrm{T}$ cells in conjunction with an autologous stem cell transplantation [14]. Thus, CD19 might be the potential target for multiple myeloma treatment. Moreover, sequential delivery of BCMA-CAR and CD19-CAR T cells resulted in a strong therapeutic outcome; preliminary data suggested that amplification of CD19-CAR T cells might be critically associated with this response and even the absence of even minimal residual disease [15]. However, it is critical to note that patients diagnosed with associated lymphocytopenia may not have enough $\mathrm{T}$ cells for the production of two CAR $\mathrm{T}$ products; high manufacturing costs are also a key limitation to be considered. We also note that sequential delivery of two independent CAR $\mathrm{T}$ products might be associated with limited efficacy of the second infusion [16]. Previous study proved bi-specific CAR capable of preventing antigen escape in vivo by post-mortem analysis which revealed the outgrowth of CD19- mutants in the mixed-Raji xenograft [17]. Taken together, these results suggest that we might employ CAR T cells that simultaneously recognize both CD19 and BCMA for effective treatment of MM and reduce the risk of relapse.

Here, we describe a novel CAR lentiviral construct with tandem alignment of a dual scFv (tan-CAR) targeting both CD19 and BCMA antigens. To the best of our knowledge, this is the first time this approach has been considered. Among our results, we found that tan-CAR $\mathrm{T}$ cells targeting one or both antigens promote equivalent cytotoxic effects in vitro as do conventional CAR T cells with only a single scFv. Interestingly, the results of our in vivo studies suggested that tan-CAR $\mathrm{T}$ cells were capable of eradicating a mix of malignant cells that express CD19 or BCMA, ultimately resulting in complete remission. As such, our results suggest that the tandemdual antigen targeting strategy will represent effective anti-neoplastic therapy may ultimately prevent relapse secondary to absence or loss of BCMA expression on the malignant MM cells.

\section{Methods \\ Plasmid construction and production of recombinant lentiviral vectors}

The tandem-CAR construct is a second-generation vector consisting of the following components in-frame from the $5^{\prime}$ end to the $3^{\prime}$ end: the CD8 signal peptide sequence, anti-BCMA-scFv (C11D5.3) [18], anti-CD19 scFv (FMC63AA 1-267, GenBank ID: HM852952.1), the hinge and transmembrane regions of the CD $8 \alpha$ molecule, the cytoplasmic domain of CD28, and the CD3 zeta signaling domain. The sequence was synthesized by Tsingke Biological Technology (Shanghai, China) and cloned into the pUT plasmid backbone (Unicar-Therapy Biomedicine Technology Co., Ltd., Shanghai, China). The newly-constructed lentiviral vector is referred to as tan-CAR. We also prepared the $\mathrm{scFv}$ domain CAR vectors CD19-CAR and BCMA-CAR with the CD8 signal peptide sequence anti-CD19 scFv (FMC63AA 1-267, GenBank ID: HM852952.1) or anti-BCMA-scFv (C11D5.3), the hinge and transmembrane regions of the CD $8 \alpha$ molecule and cytoplasmic domain of CD28 and the CD3 zeta signaling domain. Lentiviruses were generated from these constructs via transient transfection of HEK293T cells.

\section{Cell lines}

All the cell lines were purchased from the American Tissue Culture Collection (Manassas, VA, USA) and cultured in Roswell Park Medical Institute (RPMI)-1640 medium supplemented with $10 \%$ heat-inactivated fetal bovine serum (FBS; HyClone, Logan, UT, USA). K562 cells were stably 
transduced with the lentiviral constructs encoding CD19 or BCMA and luciferase. Following transduction, single luciferase-positive cells were selected for clonal expansion. K562-CD19-luc and K562-BCMA-luc stable cell lines were generated by this method. Myeloma cell line 8226 were transduced with the lentiviral constructs encoding CD19 to obtain the tumor cells expressing both CD19 and BCMA.

\section{Preparation of CAR T cells}

Healthy donor-derived peripheral blood mononuclear cells were isolated from blood by gradient centrifugation using Lymphoprep ${ }^{\text {Tx }}$ (Oriental Hua Hui, Beijing, China) followed by $\mathrm{CD}^{+}{ }^{+} \mathrm{T}$-cell enrichment by positive selection using a magnetic bead separation method (Miltenyi Biotec, Bergisch Gladbach, Germany). $\mathrm{CD}^{+} \mathrm{T}$ cells were cultured and activated in vitro using anti-CD3/CD28 monoclonal antibodies (Miltenyi Biotec) in a $5 \% \mathrm{CO}_{2}$ atmosphere at $37^{\circ} \mathrm{C}$ for $18-24 \mathrm{~h}$. The activated $\mathrm{T}$ cells were then transduced with lentivirus (CD19-CAR, BCMA-CAR and tandem CAR) for $48 \mathrm{~h}$. We also tansduced the BCMA CAR (D1) followed by CD19-CAR (D2) to obtain the T cells expressed two scFv by transduced two lentivirus. After transduction, the CAR T cells were cultured and expanded in a $5 \% \mathrm{CO}_{2}$ atmosphere at $37^{\circ} \mathrm{C}$ for 14 days in AIM-V medium (Gibco, Grand Island, NY, USA), supplemented with $100 \mathrm{IU} / \mathrm{mL}$ recombinant human interleukin-2 (IL-2; Peprotech, Rocky Hill, NJ, USA), $5 \mathrm{ng} / \mathrm{ml}$ recombinant human IL-7 (Peprotech), $5 \mathrm{ng} / \mathrm{mL}$ recombinant human IL-15 (Peprotech) and 10\% autologous plasma [19].

\section{Flow cytometry}

For the flow cytometry assays, the cells were harvested and washed twice with $1 \mathrm{~mL}$ of phosphate-buffered saline (PBS) containing 2\% FBS (Gibco). To determine transduction efficiency and the CD4/CD8 ratio, the CAR $\mathrm{T}$ cells were labeled with the recombinant protein $\mathrm{L}$ FITC (ACRO Biosystems, Beijing, China), anti-CD4-PECy7 (eBioscience, San Diego, CA), and anti-CD8-APC (eBioscience) for $45 \mathrm{~min}$ at $4{ }^{\circ} \mathrm{C}$ in the dark. For detection of the CD19 CAR-expressing $\mathrm{T}$ cells, the CAR $\mathrm{T}$ cells were incubated with human CD19 protein-FITC (ACRO) for $45 \mathrm{~min}$ at $4{ }^{\circ} \mathrm{C}$ in the dark. For detection of the BCMA-CAR $\mathrm{T}$ cells, the CAR $\mathrm{T}$ cells were labeled with human BCMA protein-FITC (ACRO) for $45 \mathrm{~min}$ at $4{ }^{\circ} \mathrm{C}$ in the dark. The cells were washed twice before analysis by Attune NxT flow cytometer (Thermo Fisher, Waltham, USA).

\section{T-cell activation assay}

T-cell activation was evaluated by measuring CD69 expression on tan-CAR $\mathrm{T}$ cells in response to $24-\mathrm{h}$ coculture with target cells. Un-transduced (NC) T cells were used as negative controls, and the $\mathrm{T}$ cells transduced with CD19-CAR or BCMA-CAR served as positive controls. After co-culture, the cells were harvested and washed twice with $1 \mathrm{~mL}$ of PBS containing 2\% FBS and then labeled with CD69-PE (Biolegend, San Diego, CA, USA), CD3-FITC (Biolegend), and protein LFITC (ACRO) for $20 \mathrm{~min}$ at room temperature in the dark. CD69 expression in CAR T cells as detected by flow cytometry was used as a marker of CAR T-cell activation.

\section{Quantitation of T-cell proliferation}

Cell proliferation assays were performed using a Carboxyfluorescein Diacetate Succinimidyl Ester (CFSE) assay kit (Abcam, Cambridge, UK) following the manufacturer's instructions. In brief, the CAR T cells were labeled with $2.5 \mu \mathrm{M}$ CFSE and then co-cultured with Raji cells which treated with mitomycin before to stop the division, at a stimulator to responder ratio of $2: 1\left(10^{6}\right.$ CAR T cells $/ \mathrm{mL}$ ) for 5 days in 96-well plates in $200 \mu \mathrm{L}$ serum-free AIM-V (Gibco) medium per well. Flow cytometry was performed using an Attune NxT flow cytometer (Thermo Fisher) to detect changes in CFSE intensity. FlowJo V10 software (TreeStar, San Carlos, CA, USA) was used for data analysis.

\section{Cytotoxicity assays}

Cytotoxicity was determined via quantitation of lactate dehydrogenase activity in the supernatants of effector and target cell co-cultures using the Cytotoxicity Detection Kit (Promega, Madison, WI, USA) following the manufacturer's protocol. All the transduced CAR T cells (effector, E) were co-cultured with cells of the target cells that overexpressed CD19, BCMA, or both antigens (target, T) at E:T ratios of 5:1, 2.5:1, and 1:1, respectively. Target and effector cells were seeded in 96-well plates in a total volume of $100 \mu \mathrm{L}$ of serum-free RPMI 1640 media (Gibco) and incubated at $37^{\circ} \mathrm{C}$ for $6 \mathrm{~h}$. After coculture, $50 \mu \mathrm{L}$ of cell-free supernatant from each well was transferred to a new 96-well plates and mixed with equal volume of lactic acid dehydrogenase substrate mixture for $20 \mathrm{~min}$ at room temperature in the dark. The absorbance was recorded at $492 \mathrm{~nm}$ using a full wavelength reader Multiskan GO (Thermo Scientific). Tumor (target cell) lysis was calculated with the following formula: \% lysis = $($ experimental LDH release - spontaneous LDH release) / (maximum LDH release spontaneous LDH release) $\times 100$.

\section{Detection of CD107a}

To evaluate CD107a expression on the cell surface as an indirect marker of degranulation, $10^{6} \mathrm{CAR} \mathrm{T}$ cells were co-cultured with target cells at a 5:1 ratio in 96-well plates with a total of $200 \mu \mathrm{L}$ of AIM-V (Gibco) medium per well for $6 \mathrm{~h}$. The Golgi inhibitor monensin 
(Invitrogen, Carlsbad, CA, USA) was added before the incubation. Cocktails (Invitrogen) were added to the positive control group before co-culture. After a 6-h incubation, cells were labeled with anti-CD107a-APC, anti-CD3-FITC, and anti-CD8-PE. All the antibodies were purchased from Becton, Dickinson and Company Co., Ltd. (Franklin Lakes, NJ, USA). Cells were collected, washed twice with PBS, and flow cytometry analysis was performed on an Attune NxT flow cytometer (Thermo Fisher). The results were analyzed by FlowJo V10 software (TreeStar).

\section{Analysis of cytokine release}

Cytokine release was evaluated using a Th1/Th2 Cytometric Bead Array (CBA) Kit II (BD Bioscience) according to the manufacturer's instructions. Briefly, CARtransduced $\mathrm{T}$ cells were co-cultured with the various K562 cell transfectants at an E:T ratio of 5:1 in a 96-well plate with a total volume of $200 \mu \mathrm{L}$ of RPMI 1640 medium (Gibco). After $24 \mathrm{~h}$ in co-culture, cell-free supernatants were harvested and the levels of various cytokines were evaluated. The capture microspheres for seven specific cytokines (IL-2, IL-4, IL-6, IL-10, IFN- $\gamma$, TNF-a, and IL-17A) were first mixed and then incubated with the sample and fluorescent antibody for $3 \mathrm{~h}$. The mixture was washed and cytokine concentrations were determined by flow cytometry (Thermo Fisher). The concentration of each cytokine was calculated from standard curves.

\section{Mouse xenograft model}

Mouse experiments were performed with the approval of the Institutional Animal Care and Use Committee of East China Normal University. Four-to-six-week-old male NOD/scid $/ \mathrm{\gamma c}^{-/-}$(NSG) mice were purchased from Biocytogen Co., Ltd. (Beijing, China). Xenograft models were established via injection of K562-CD19-luc and/or K562-BCMA-luc cells. A total of $7 \times 10^{6}$ mixed tumor cells at a ratio of 1:1 in $200 \mu \mathrm{L}$ PBS were injected into mice via the tail vein on day 0 . The mice were then randomly divided into four groups that received either (a) $10^{7}$ CD19-CAR T cells $(n=3)$, (b) $10^{7}$ BCMA-CAR T cells $(\mathrm{n}=3),(\mathrm{c}) 10^{7}$ tan-CAR T cells $(\mathrm{n}=3)$ or $(\mathrm{d}) 10^{7}$ un-transduced $T$ cells $(n=3$, negative control) via the intravenous route on both days 8 and 10. The mice injected with K562-CD19-luc or K562-BCMA-luc were treated with CD19-CAR T or BCMA-CAR T cells, respectively. Tumor progression was monitored by bioluminescent imaging every 4 days beginning on day 7 . The mice were sacrificed when moribund or upon the development of hind-limb paralysis. For in vivo imaging, the mice were injected intraperitoneally with $150 \mathrm{mg} / \mathrm{kg}$ D-luciferin (Yeasen, Shanghai, China) and imaged under isoflurane anesthesia using the Xenogen-IVIS system
(LI-COR Biosciences, Lincoln, NE, USA). Fluorescence was quantified using Living Image software (IVIS Lumina Series, PerkinElmer, Waltham, MA, USA).

\section{Statistical analysis}

Statistical analyses were carried out using GraphPad Prism 8.0. Biological replicates of in vitro $(n=3)$ and in vivo data $(\mathrm{n}=3)$ are presented as the mean \pm SD. Statistical analysis was performed to assess differences between individual treatment groups and the un-transduced control group using one-way ANOVA. Statistically significant findings were defined as $* p<0.05$.

\section{Results}

\section{Generation and characterization of the tan-CAR-} transduced T cells

To develop and to evaluate a CAR T-cell strategy that facilitated simultaneous targeting of both CD19 and BCMA, we designed and generated a novel CAR construct with tandem orientation of both CD19-scFv and BCMA-scFv domains. This tandem-CAR $\mathrm{T}$ also included

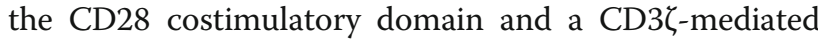
activation signaling component. In parallel, we constructed two control CAR Ts with single scFv domains from anti-CD19 (CD19-CAR) and anti-BCMA (BCMACAR) with otherwise identical components (Fig. 1a). Transduction efficiency of the lentiviral vectors that contain the tan-CAR, the CD19-CAR, and the BCMA-CAR targeting primary $\mathrm{T}$ cells was evaluated. The surface expression of each of these antigens upon T-cell transduction typically yielded 46 to $55 \%$ positive cells; this was verified by flow cytometry using L-protein-FITC to detect cell surface expression of variable light chains (Fig. 1b). Similarly, to validate co-expression of both CD19 and BCMA on tan-CAR-transduced $\mathrm{T}$ cells, we introduced tan-CAR effector cells to human CD19 protein or human BCMA protein to define specific CAR T cell detection (for details, see Methods). We found that tanCAR-transduced T cells expressed both scFvs; $59 \%$ were BCMA-scFv-positive and 53\% were CD19-scFv-positive; these levels are comparable to those of the single scFv CAR T transductants. Similar results were obtained by flow cytometric detection with FITC-conjugated L protein (Fig. 1b). These results suggested that the tandem fusion of two scFv domains could successfully generate CAR T cells with equivalent expression of both receptor antigens. We also examined the impact of the tan-CAR construct on the CD4/CD8 T-cell ratio (Fig. 1c). As shown, tan-CAR $\mathrm{T}$ cells generated a comparable CD4 to CD8 transduced $\mathrm{T}$-cell ratio to those that resulted after T-cell transduction with either CD19-CAR or BCMACAR constructs. These results suggest that we might anticipate similar anti-tumor efficacy from all three types of CAR T cells. 
A

CD19-CAR

\begin{tabular}{|l|l|l|}
\hline CD19 scFv & 目 CD28 & CD3弓 \\
\hline
\end{tabular}

BCMA-CAR

\begin{tabular}{|l|l|l|}
\hline$G C M A$ & ScFv & 目 \\
\hline
\end{tabular}

$\tan -\mathrm{CAR}$

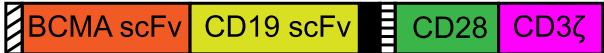

目CD8 Signal Peptide CD8a Hinge 貝CD8a TM

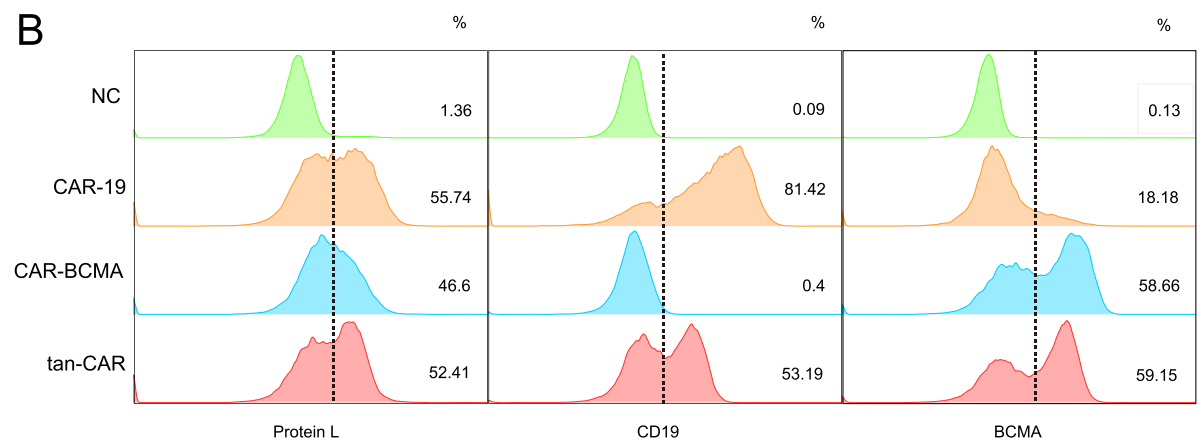

C

CD19-CAR

BCMA-CAR

tan-CAR
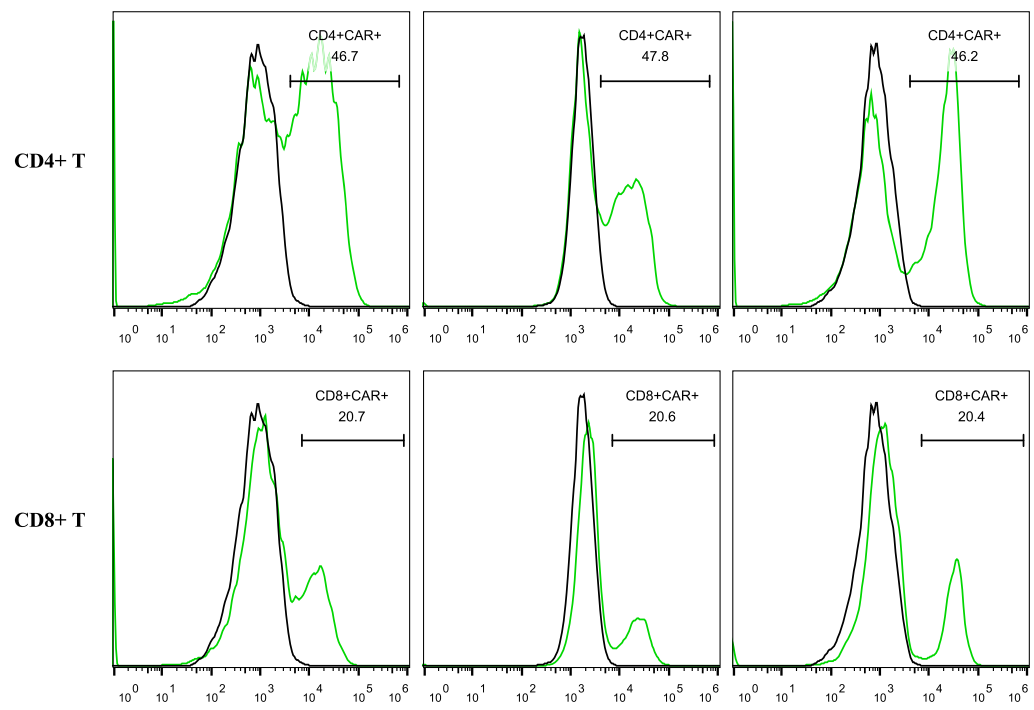

Fig. 1 Generation and characterization of tan-CAR T cells. (a) Schematic representation of the plasmid design used to construct single and tandem scFv-CAR-modified T cells. The tan-CAR construct encodes a tandem fusion of the BCMA-scFv and CD19-scFv domains, a CD28 costimulatory domain, and a CD3 zeta-mediated activation signaling domain. (b) Analysis of transduction efficiency. Isolated and activated human T cells were transduced with the lentiviral vectors CD19-CAR, BCMA-CAR, or tan-CAR. Transduction efficiency was evaluated by flow cytometry using fluorescent-tagged protein $L$ to detect variable light chain lg together with human CD19 and human BCMA protein. (c) Quantitative evaluation of $\mathrm{CD}^{+} / \mathrm{CD}^{+}{ }^{+} \mathrm{T}$-cell ratios. CAR-positive $\mathrm{CD} 4^{+} \mathrm{T}$ cells and CAR-positive $\mathrm{CD} 8^{+} \mathrm{T}$ cells were detected by flow cytometry. Data are representative of three donors 


\section{Tan-CAR-transduced T cells are activated by CD19 and} BCMA antigens

CD69 is a standard marker for T-cell activation [20, 21]. To demonstrate antigen-specific activation of tan-CARtransduced T cells, cells from the K562 human leukemia line were transfected with lentiviruses encoding CD19 and/or BCMA in order to generate K562-CD19, K562-BCMA, or K562-CD19 + BCMA cells. T-cell activation in response to co-culture with target cells expressed different antigens was analyzed by expression of CD69 on the T-cell surface (Fig. 2a). The tan-CAR $\mathrm{T}$ cells responded to both K562-CD19, K562-BCMA, and K562-CD19 + BCMA cells; CD69 expression was detected at levels that were comparable to those observed on activated CD19-CAR and BCMA-CAR $\mathrm{T}$ cells. These data indicated that tan-CAR $\mathrm{T}$ cells not only express appropriate cell surface antigens but can also be activated by CD19 and BCMA individually or when both are combined. The extent of activation was

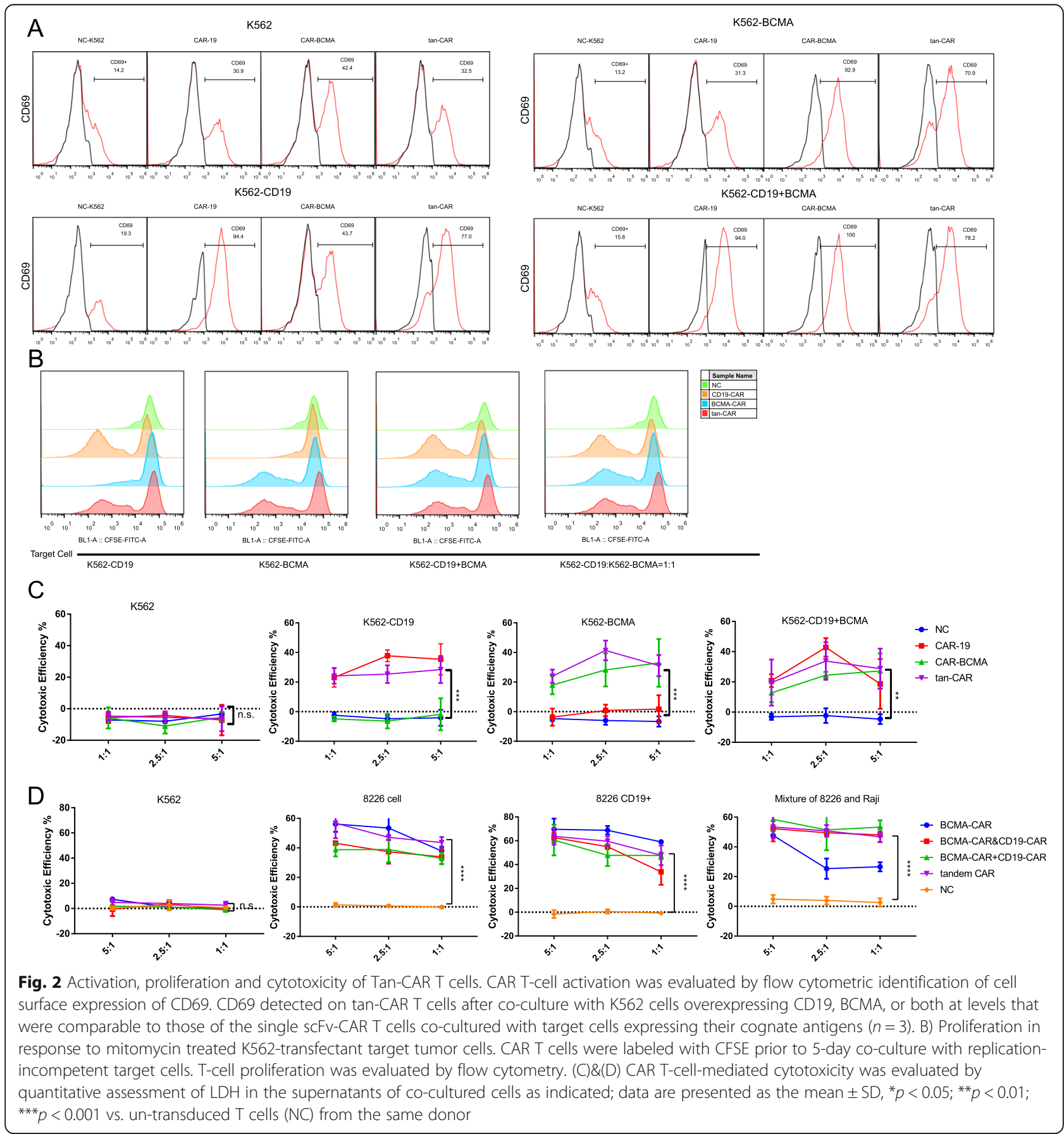


comparable to that detected among the more conventional single scFv-CAR T cells.

\section{Tumor cell-induce T-cell proliferation in response to CD19 or BCMA}

CAR T-cell proliferation upon recognition of the tumor cell antigen is a fundamental principle and crucial factor underlying the augmented anti-tumor efficacy of CAR T cells [22]. Our next step was to determine whether the proliferation of the tan-CAR $\mathrm{T}$ cells was dependent on tumor cell-specific expression of CD19 and/or BCMA.

The three different types of CAR $T$ cells were labeled with CFSE and then placed into co-culture with their corresponding target cells; T-cell proliferation was evaluated via detection of decreasing concentrations of the fluorescent dye by flow cytometry. We found that the tan-CAR $\mathrm{T}$ cells underwent extensive proliferation in response to activation by target K562 cells overexpressing CD19 and/or BCMA at an effector: target ratio of 1:1. As anticipated, tan-CAR $T$ cells proliferated to an extent that was similar to those of their corresponding single scFv CAR $\mathrm{T}$ positive counterparts. In contrast, the NC (control) T cells underwent only limited proliferation after incubation with the target K562 transfected cells (Fig. 2b). Taken together, these results indicated that both single scFv- and tan-CAR $\mathrm{T}$ cells exert significant proliferative activities in response to specific antigen stimulation.

\section{Determination of the cytotoxic efficacy and specificity of tan-CAR T cells}

To evaluate cytolytic specificity of tan-CAR $\mathrm{T}$ cells, we first determined the baseline levels of $\mathrm{LDH}$ released from target cells over the time course of the experiment. Effector cells including CD19-CAR T, BCMA-CAR T, tan-CAR T, and untransfected NC T cells were co-cultured with target cells, including K562-CD19, K562-BCMA, K562-CD19 + BCMA and wild-type (un-tranfected) K562 cells as the negative control. After $6 \mathrm{~h}$, significant cytotoxicity was observed in cocultures of tan-CAR T cells with each of the three transfected K562 target cell groups. As anticipated, CD19-CAR and BCMA-CAR T cells were cytotoxic for their corresponding target cells only; the negative control effector $\mathrm{T}$ cells (NC-T) had no cytotoxicity for any of the K562 target cells (Fig. 2c).

We also carried out another experiment to compared the cytolytic efficiency of different effector $\mathrm{T}$ cells including: a mixture of CD19-CAR $\mathrm{T}$ cells and BCMA-CAR $\mathrm{T}$ cells with the ratio of 1:1, the $\mathrm{T}$ cells transduced with BCMACAR followed by CD19-CAR lentivirus, single scFv-CAR T cells and NC T cells. As for target cells, we use the myeloma cell line of 8226, 8226 cells expressing CD19 antigen and a mixture of 8226 and Raji cells at a ratio of 1:1. After $24 \mathrm{~h}$ co-culture, as we expected, the tan-CAR showed great cytolytic efficiency towards all kinds of target cells compared with NC T cells (Fig.2d). No significant differences observed among tan CAR T cells, a mixture of two single $\mathrm{scFv} \mathrm{T}$ cells and $\mathrm{T}$ cells transduced with two lentiviruses. Importantly, BCMA-CAR-T showed slightly less cytolytic ability towards the mixture of 8226 cells and Raji cells compared with tan CAR $\mathrm{T}$ cells group, indicating BCMA-CAR $T$ cells were cytotoxic for their corresponding target cells only, but not CD19 antigen positive target cells.

\section{Determination of CD107a and cytokines release of Tan- CAR T cells}

Next, we determined whether cytolytic function was associated with a quantitative increase in the cell surface expression of the lysosomal protein CD107a. After 6-h co-culture with target K562 transfectants, elevated levels of CD107 were detected on tan-CAR T cells compared to levels detected on NC T cells. In parallel, a similar degree of CD107 up-regulation was detected in the CD19CAR and BCMA-CAR T cells, but only in response to K562 cells expressing their corresponding activating antigen (Fig. 3a).

Finally, proinflammatory cytokine release from CAR T cells was evaluated. We measured cytokine levels in coculture supernatants using the Th1/Th2 CBA Kit II. As anticipated, the tan-CAR $\mathrm{T}$ cells released cytokines to an extent that was comparable to that generated by CD19CAR and BCMA-CAR $T$ cells in response to their respective cognate antigens. Interestingly, NC-T cells also released proinflammatory cytokines, albeit to a more limited extent, when encountering the target K562 cells (Fig.3b). Collectively, these experiments demonstrated that $\tan$-CAR T-cell-mediated cytotoxicity is equivalent to that of conventional CAR $\mathrm{T}$ cells.

\section{Tan-CAR-transduced T cells are effective at promoting clearance of tumor cells in vivo}

We then performed an in vivo study that was designed to evaluate tumor regression in a mouse xenograft model. In this model, NSG mice were injected with target cells including K562-CD19-luc, K562-BCMA-luc, or the mixture of the two target cells at a 1:1 ratio on day 0 . These mice were then treated with tan-CAR $\mathrm{T}$ cells, CD19-CAR $\mathrm{T}$ cells, BCMA-CAR T cells, or NCs on day 8 and day 10 (Fig. 4a) and tumor growth was monitored by IVIS imaging; representative images depicting tumor progression or elimination are shown in Fig. 4b. Among the mice that received either K562-CD19-luc or K562-BCMA-luc target cells, those treated with their respective single scFv-CAR $\mathrm{T}$ cells experienced a significant decrease in overall tumor burden based on bioluminescence imaging analysis. However, neither of the single scFv-CAR T cells were capable of inhibiting overall tumor growth in mice with the mixed antigen tumor xenograft. By contrast, tan-CAR $\mathrm{T}$ cells showed an efficient anti-tumor inhibitory response and were able to promote tumor regression in all three 

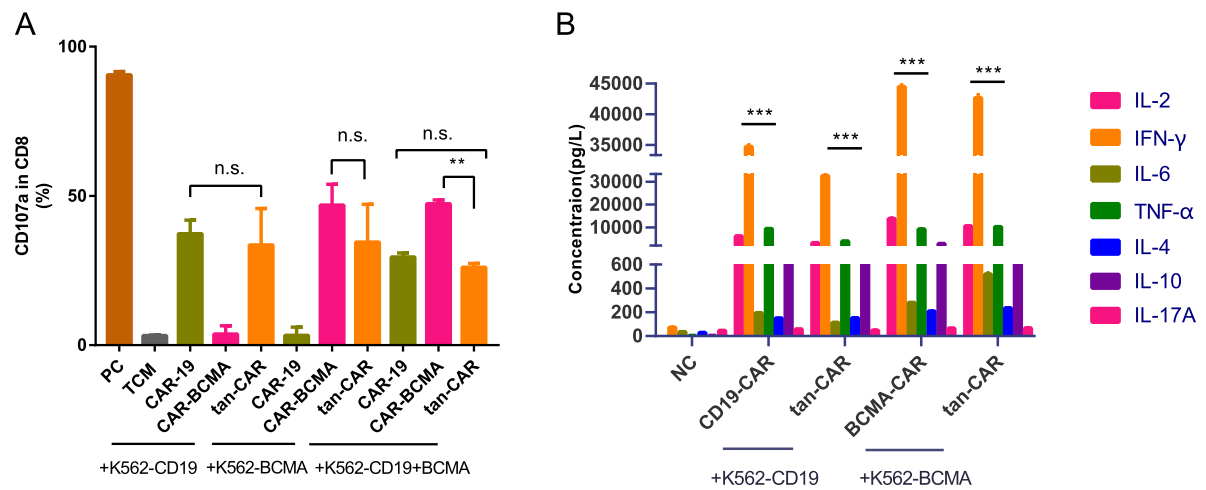

Fig. 3 CD107a and cytokines release of Tan-CAR T cells responded to antigen-expressing tumor cells. (a) Degranulation of modified T cells was assessed by the appearance of lysosomal protein CD107a on the surface of the CAR T cells in response to co-culture as described. (b) Cytokine release in response to co-culture of CAR T cells and target K562 cells as indicated; cytokines evaluated include IL-2, IL-4, IL-6, IL-10, TNF-a, IFN- - , and IL-17A. Bars represent the mean \pm SD of replicate samples. Data are representative of three independent experiments, each with CAR T cells generated from peripheral blood T cells from a different donor

xenograft models. The signal intensity from IVIS imaging as a function of time is shown in Fig. 4c. These results demonstrated that the conventional single scFV-CAR $\mathrm{T}$ cells directed against either CD19 or BCMA were capable of targeting tumor cells that express the corresponding antigens but had no impact on other tumor cells. Most notably, the tan-CAR $\mathrm{T}$ cells had a remarkable and specific anti-tumor effect in vivo toward tumor cells that were CD19-, BCMA-positive, or both $(p<0.05)$. Taken together with the results of our in vitro experiments, tan-CAR $\mathrm{T}$ cells promote the successful elimination of tumor cells that express either CD19, BCMA, or both; our tan-CAR T cells demonstrate high antigen specificity and in vivo efficacy that is comparable to conventional those of single scFv-CAR T cells.

\section{Discussion}

Adoptive transfer of engineered $\mathrm{T}$ cells is a promising approach for the treatment of cancer; unfortunately, post-treatment relapse remains a significant challenge, results suggesting that these therapeutic agents might require further optimization [12]. For example, adoptive transfer of anti-BCMA-CAR $\mathrm{T}$ cells to patients with refractory or relapsed MM was initially met with a positive therapeutic response; however, relapse can occur very quickly after the completion of CAR T-cell therapy [12, 23]. This may be related to the absence of the target antigen from the tumor cell surface that has been observed in response to single scFV-CAR T-cell therapy [12]; Previous data showed CD19 expression on plasma cells with characterized cancer stem cell- like properties is a poor prognostic indicator [24]. Clinical data [15] showed BCMA-CAR combined CD19-CAR T cells resulted in MRD negative completely remission leading us to develop tandem CAR-T targeting both CD19 and BCMA, reducing the cost of manufacturing two kind of
CAR-T products, while achieving maintaining the longterm remission of patients.

The linkage of two scFvs into a single tandem-CAR in order to generate a bi-specific chimeric receptor has already been proposed in theory [25], although, to the best of our knowledge, this is the first evidence for its successful execution. The tan-CAR enables $\mathrm{T}$ cells to recognize two distinct target antigens and to initiate specific killing of the tumor cells that express one or both of the cognate antigens. Perhaps the most critical component of the tan-CAR design is the need to ascertain cytotoxic efficacy that is at least comparable to that of the conventional single scFv-CAR.

To limit the potential for relapse after completion of therapy with BCMA-CAR T cells, we aligned the scFv of anti-CD19 with that of anti-BCMA in a single targeting domain to generate tandem-CAR (tan-CAR). This tanCAR construct was used successfully to transduce primary human $\mathrm{T}$ cells (tan-CAR $\mathrm{T}$ cells). In this study, we carefully evaluated the specificity and efficacy of the tanCAR $T$ in vitro and with respect to a xenograft disease model. Accordingly, this dual scFv CAR construct was activated by either BCMA or CD19 antigens. Moreover, $\tan$-CAR $\mathrm{T}$ cells were highly efficacious against antigenspecific tumor cells in both in vitro and in vivo experiments with responses that were comparable to the single scFv-CAR T cells directed against BCMA or CD19. The intrinsic utility of tan-CAR T-cell therapy was also investigated using an immunodeficient mouse model bearing K562-CD19-luc and K562-BCMA-luc target tumor cells. We determined that tan-CAR T-cell specificity and efficacy was fully comparable to those of its single scFvCAR T counterparts. Notably, tan-CAR enabled T cells to recognize one or both relevant antigens and significantly limited tumor progression in combined target tumor model in mice; by contrast, the tumor burden in 
A CAR-T cells or NC T cells

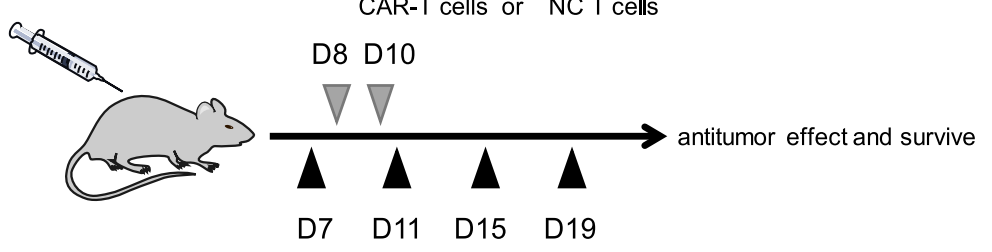

tumor cells injection

BLI cytokines

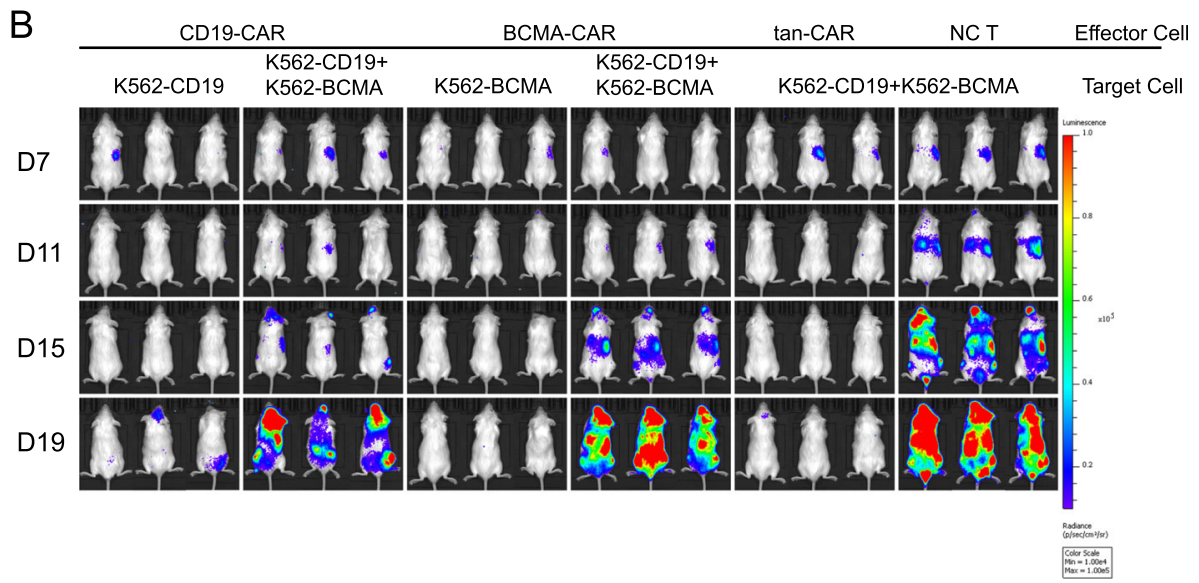

C

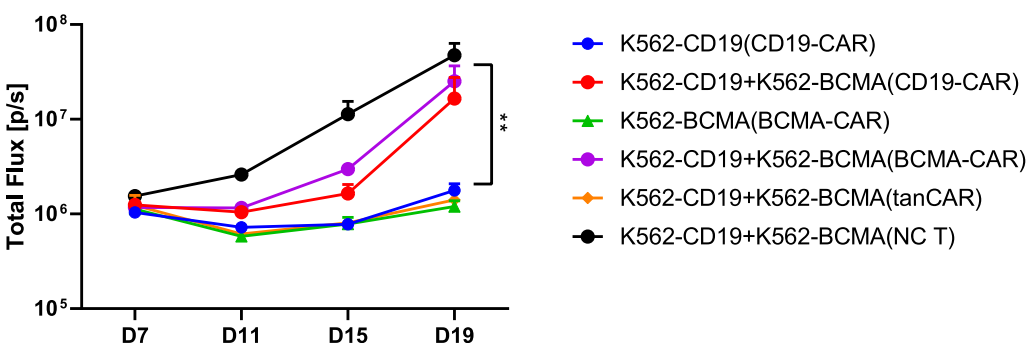

Fig. 4 Tan-CAR-transduced T cells effectively clear tumors in vivo. (a) Schematic of the xenograft model used to investigate the activity of tanCAR T cells in vivo. NSG mice were injected with $7 \times 10^{6} \mathrm{~K} 562$-transduced luciferase-positive target cells via the tail vein; bioluminescent imaging was performed on day 7 and every 4 days thereafter. CAR T cells $\left(10^{7}\right)$ or NC T cells $\left(10^{7}\right)$ were provided by intravenous injection on days 8 and 10. (b) Bioluminescence radiance was used as a surrogate marker for tumor burden. (c) Time course of tumor growth based on mouse wholebody bioluminescence. The mean signal per mouse \pm SD is as shown. Statistical analysis was performed using day 19 data (the last time point at which a sufficient number of mice that did not receive treatments remained viable) using one-way ANOVA followed by Tukey's multiple comparisons test. The data are presented as the mean $\pm \mathrm{SD}(n=3) ;{ }^{* *} p<0.001$

the mixed target model increased rapidly in single scFv CAR T-treated mice. Therefore, the bivalent nature of tan-CAR can promote specific T-cell-mediated inhibition of tumor cells that express CD19 and/or BCMA antigen, while the impact of single scFv-CAR $\mathrm{T}$ cells was limited to their corresponding single antigen-positive tumor cells.

In summary, we present here the first report of an extensive pre-clinical characterization of novel dual tandem CD19/BCMA-scFv-CAR $T$ cells which were developed for the treatment of refractory or relapsing MM. Our study demonstrated that the tan-CAR which included two specific scFvs from anti-CD19 and antiBCMA promoted cytolysis of target tumor cells via activation via both CD19 and BCMA. Given the known obstacles to effective CAR T-cell therapy, including absence or loss of BCMA expression, the capacity to target two critical antigens with a single cell infusion could be a promising approach toward addressing problems of refractory disease and disease recurrence. This novel approach might also serve to reduce production costs that would be encountered in providing sequential CAR Tcell treatment for myeloma.

\section{Conclusion}

We report here the design, generation, and evaluation of $\tan -\mathrm{CAR} \mathrm{T}$ cells that can recognize both CD19 and BCMA B-cell antigens, and that can exert significant 
in vitro and in vivo cytotoxic effects against tumor cells that express one or both of these antigens. This novel and highly effective tan-CAR construct may ultimately be the basis for a novel and effective option for treatment of refractory and recurrent MM, notably among those who have relapsed after effective BCMA-CAR Tcell treatment.

\section{Abbreviations}

NC: Untransduced T cell; scFv: Single-chain variable fragment; tanCAR: Tandem-chimeric antigen receptor; BCMA: B cell maturation antigen; PC: Positive control; TCM: T cell medium; CAR: Chimeric antigen receptor; BCMA: B cell maturation antigen; IL-2: Interleukin 2; IL-4: Interleukin 4; IL6: Interleukin 6; IL-10: Interleukin 10; TNF-a: Tumor necrosis factor-alpha; IFNү: Interferon gamma; IL-17A: Interleukin 17A; NC T: Negative control T cells

\section{Acknowledgements}

We thank Masuma Akter Monty for revising the manuscript.

\section{Protection of animal subjects}

The institutional and national guidelines for the care and use of laboratory animals were followed and overseen by the animal facility of the East China Normal University.

\section{Authors' contributions}

LY, DPW, LQK contributed to the concept development and study design and wrote the manuscript. NX and MHL participated in the figure preparation and revised the paper. All authors read and approved the final manuscript.

\section{Funding}

This key project was funded by Shanghai Science and Technology Commission (No.19431903800) in China.

\section{Availability of data and materials}

The data-sets used and/or analyzed during the current study are available from the corresponding author on reasonable request.

\section{Ethics approval and consent to participate}

Not applicable.

\section{Consent for publication}

Not applicable.

\section{Competing interests}

The authors declare no conflict of interest.

\section{Author details}

${ }^{1}$ Institute of Biomedical Engineering and Technology, Shanghai Engineering Research Center of Molecular Therapeutics and New Drug Development, School of Chemistry and Molecular Engineering, East China Normal University, NO, 3663 North Zhongshan Road, Shanghai 200065, China ${ }^{2}$ National Clinical Research Center for Hematologic Diseases, Jiangsu Institute of Hematology, The First Affiliated Hospital of Soochow University, Suzhou, China. ${ }^{3}$ Institute of Blood and Marrow Transplantation, Collaborative Innovation Center of Hematology, Soochow University, Suzhou, China. ${ }^{4}$ Shanghai Unicar-Therapy Bio-medicine Technology Co., Ltd, No 1525 Minqiang Road, Shanghai 201612, China. ${ }^{5}$ Central Laboratory of Hematology and Oncology, First Affiliated Hospital, Harbin Medical University, Harbin 150001, Heilongjiang Province, China.

Received: 9 March 2020 Accepted: 27 April 2020

Published online: 13 May 2020

\section{References}

1. Kumar SK, Rajkumar SV, Dispenzieri A, Lacy MQ, Hayman SR, Buadi FK, Zeldenrust SR, Dingli D, Russell SJ, Lust JA, Greipp PR, Kyle RA, Gertz MA. Improved survival in multiple myeloma and the impact of novel therapies. BLOOD. 2008;111:2516-20.
2. Mailankody S, Korde N, Lesokhin AM, Lendvai N, Hassoun H, StetlerStevenson M, Landgren O. Minimal residual disease in multiple myeloma: bringing the bench to the bedside. Nat Rev Clin Oncol. 2015;12:286-95.

3. Korde N, Roschewski M, Zingone A, Kwok M, Manasanch EE, Bhutani M, Tageja N, Kazandjian D, Mailankody S, Wu P, Morrison C, Costello R, Zhang Y, Burton D, Mulquin M, Zuchlinski D, Lamping L, Carpenter A, Wall Y, Carter G, Cunningham SC, Gounden V, Sissung TM, Peer C, Maric I, Calvo KR, Braylan R, Yuan C, Stetler-Stevenson M, Arthur DC, Kong KA, Weng L, Faham M, Lindenberg L, Kurdziel K, Choyke P, Steinberg SM, Figg W, Landgren O. Treatment With Carfilzomib-Lenalidomide-Dexamethasone With Lenalidomide Extension in Patients With Smoldering or Newly Diagnosed Multiple Myeloma. JAMA ONCOL 2015;1:746.

4. Jakubowiak AJ, Dytfeld D, Griffith KA, Lebovic D, Vesole DH, Jagannath S, AlZoubi A, Anderson T, Nordgren B, Detweiler-Short K, Stockerl-Goldstein K, Ahmed A, Jobkar T, Durecki DE, McDonnell K, Mietzel M, Couriel D, Kaminski M, Vij R. A phase 1/2 study of carfilzomib in combination with lenalidomide and low-dose dexamethasone as a frontline treatment for multiple myeloma. BLOOD. 2012;120:1801-9.

5. Kochenderfer JN, Dudley ME, Kassim SH, Somerville RP, Carpenter RO, StetlerStevenson M, Yang JC, Phan GQ, Hughes MS, Sherry RM, Raffeld M, Feldman S, Lu L, Li YF, Ngo LT, Goy A, Feldman T, Spaner DE, Wang ML, Chen CC, Kranick SM, Nath A, Nathan DA, Morton KE, Toomey MA, Rosenberg SA. Chemotherapy-refractory diffuse large B-cell lymphoma and indolent B-cell malignancies can be effectively treated with autologous T cells expressing an anti-CD19 chimeric antigen receptor. J CLIN ONCOL 2015;33:540-549.

6. Grupp SA, Kalos M, Barrett D, Aplenc R, Porter DL, Rheingold SR, Teachey DT, Chew A, Hauck B, Wright JF, Milone MC, Levine BL, June CH. Chimeric antigen receptor-modified $T$ cells for acute lymphoid leukemia. N Engl J Med. 2013;368:1509-18.

7. Kalos M, Levine BL, Porter DL, Katz S, Grupp SA, Bagg A, June CH. T cells with chimeric antigen receptors have potent antitumor effects and can establish memory in patients with advanced leukemia. SCI TRANSL MED 2011;3:73r-95r.

8. Galluzzi L, Vacchelli E, Bravo-San PJ, Buque A, Senovilla L, Baracco EE, Bloy N, Castoldi F, Abastado JP, Agostinis P, Apte RN, Aranda F, Ayyoub M, Beckhove P, Blay JY, Bracci L, Caignard A, Castelli C, Cavallo F, Celis E, Cerundolo V, Clayton A, Colombo MP, Coussens L, Dhodapkar MV, Eggermont AM, Fearon DT, Fridman WH, Fucikova J, Gabrilovich DI, Galon J, Garg A, Ghiringhelli F, Giaccone G, Gilboa E, Gnjatic S, Hoos A, Hosmalin A, Jager D, Kalinski P, Karre K, Kepp O, Kiessling R, Kirkwood JM, Klein E, Knuth A, Lewis CE, Liblau R, Lotze MT, Lugli E, Mach JP, Mattei F, Mavilio D, Melero I, Melief CJ, Mittendorf EA, Moretta L, Odunsi A, Okada H, Palucka AK, Peter ME, Pienta KJ, Porgador A, Prendergast GC, Rabinovich GA, Restifo NP, Rizvi N, Sautes-Fridman C, Schreiber H, Seliger B, Shiku H, Silva-Santos B, Smyth MJ, Speiser DE, Spisek R, Srivastava PK, Talmadge JE, Tartour E, Van Der Burg SH, Van Den Eynde BJ, Vile R, Wagner H, Weber JS, Whiteside TL, Wolchok JD, Zitvogel L, Zou W, Kroemer G. Classification of current anticancer immunotherapies. Oncotarget 2014;5:12472-12508.

9. Raje N, Berdeja J, Lin Y, Siegel D, Jagannath S, Madduri D, Liedtke M, Rosenblatt J, Maus MV, Turka A, Lam LP, Morgan RA, Friedman K, Massaro M, Wang J, Russotti G, Yang Z, Campbell T, Hege K, Petrocca F, Quigley MT, Munshi N, Kochenderfer JN. Anti-BCMA CAR T-cell therapy bb2121 in relapsed or refractory multiple myeloma. N Engl J Med. 2019;380:1726-37.

10. Zhao WH, Liu J, Wang BY, Chen YX, Cao XM, Yang Y, Zhang YL, Wang FX, Zhang PY, Lei B, Gu LF, Wang JL, Yang N, Zhang R, Zhang H, Shen Y, Bai J, Xu Y, Wang XG, Zhang RL, Wei LL, Li ZF, Li ZZ, Geng Y, He Q, Zhuang QC, Fan $X H$, He AL, Zhang WG. A phase 1, open-label study of LCAR-B38M, a chimeric antigen receptor $T$ cell therapy directed against $B$ cell maturation antigen, in patients with relapsed or refractory multiple myeloma. J Hematol Oncol. 2018;11:141.

11. Wu C, Zhang L, Brockman QR, Zhan F, Chen L. Chimeric antigen receptor T cell therapies for multiple myeloma. J Hematol Oncol. 2019;12:120.

12. Ali SA, Shi V, Maric I, Wang M, Stroncek DF, Rose JJ, Brudno JN, StetlerStevenson M, Feldman SA, Hansen BG, Fellowes VS, Hakim FT, Gress RE, Kochenderfer JN. T cells expressing an anti-B-cell maturation antigen chimeric antigen receptor cause remissions of multiple myeloma. BLOOD. 2016;128:1688-700.

13. Sanchez E, Gillespie A, Tang G, Ferros M, Harutyunyan NM, Vardanyan S, Gottlieb J, Li M, Wang CS, Chen H, Berenson JR. Soluble B-cell maturation antigen mediates tumor-induced immune deficiency in multiple myeloma. Clin Cancer Res. 2016;22:3383-97. 
14. Garfall AL, Stadtmauer EA, Hwang W, Lacey SF, Melenhorst JJ, Krevvata M, Carroll MP, Matsui WH, Wang Q, Dhodapkar MV, Dhodapkar K, Das R, Vogl DT, Weiss BM, Cohen AD, Mangan PA, Ayers EC, Nunez-Cruz S, Kulikovskaya I, Davis MM, Lamontagne A, Dengel K, Kerr NDS, Young RM, Siegel DL, Levine BL, Milone MC, Maus MV, June CH. Anti-CD19 CAR T cells with highdose melphalan and autologous stem cell transplantation for refractory multiple myeloma. JCl Insight. 2018;3.

15. Yan Z, Cao J, Cheng H, Qiao J, Zhang H, Wang Y, Shi M, Lan J, Fei X, Jin L, Jing G, Sang W, Zhu F, Chen W, Wu Q, Yao Y, Wang G, Zhao J, Zheng J, Li Z, Xu K. A combination of humanised anti-CD19 and anti-BCMA CAR T cells in patients with relapsed or refractory multiple myeloma: a single-arm, phase 2 trial. Lancet Haematol. 2019;6:e521-9.

16. Qin H, Ramakrishna S, Nguyen S, Fountaine TJ, Ponduri A, Stetler-Stevenson M, Yuan CM, Haso W, Shern JF, Shah NN, Fry TJ. Preclinical development of bivalent chimeric antigen receptors targeting both CD19 and CD22. Mol Ther Oncolytics. 2018;11:127-37.

17. Zah E, Lin MY, Silva-Benedict A, Jensen MC, Chen YY. T cells expressing CD19/CD20 bispecific chimeric antigen receptors prevent antigen escape by malignant B cells. CANCER IMMUNOL RES. 2016;4:498-508.

18. Carpenter RO, Evbuomwan MO, Pittaluga S, Rose JJ, Raffeld M, Yang S, Gress RE, Hakim FT, Kochenderfer JN. B-cell maturation antigen is a promising target for adoptive T-cell therapy of multiple myeloma. Clin Cancer Res. 2013;19:2048-60.

19. Li C, Zhang Y, Zhang C, Chen J, Lou X, Chen X, Kang L, Xu N, Li M, Tan J, Sun X, Zhou J, Yang Z, Zong X, Wang P, Xu T, Qu C, Huang H, Jin Z, Yu L, Wu D. Comparison of CAR-T19 and autologous stem cell transplantation for refractory/relapsed non-Hodgkin's lymphoma. JCl Insight. 2019;4.

20. Kuehl WM, Bergsagel PL. Molecular pathogenesis of multiple myeloma and its premalignant precursor. J Clin Invest. 2012;122:3456-63.

21. Zhang E, Yang P, Gu J, Wu H, Chi X, Liu C, Wang Y, Xue J, Qi W, Sun Q, Zhang S, Hu J, Xu H. Recombination of a dual-CAR-modified T lymphocyte to accurately eliminate pancreatic malignancy. J Hematol Oncol. 2018;11:102

22. Porter DL, Hwang WT, Frey NV, Lacey SF, Shaw PA, Loren AW, Bagg A, Marcucci KT, Shen A, Gonzalez V, Ambrose D, Grupp SA, Chew A, Zheng Z, Milone MC, Levine BL, Melenhorst JJ, June CH. Chimeric antigen receptor T cells persist and induce sustained remissions in relapsed refractory chronic lymphocytic leukemia. SCI TRANSL MED 2015;7:139r-303r.

23. Brudno JN, Maric I, Hartman SD, Rose JJ, Wang M, Lam N, Stetler-Stevenson M, Salem D, Yuan C, Pavletic S, Kanakry JA, Ali SA, Mikkilineni L, Feldman SA, Stroncek DF, Hansen BG, Lawrence J, Patel R, Hakim F, Gress RE, Kochenderfer JN. T cells genetically modified to express an anti-B-cell maturation antigen chimeric antigen receptor cause remissions of poorprognosis relapsed multiple myeloma. J Clin Oncol. 2018;36:2267-80.

24. Garfall AL, Maus MV, Hwang WT, Lacey SF, Mahnke YD, Melenhorst JJ, Zheng Z, Vogl DT, Cohen AD, Weiss BM, Dengel K, Kerr ND, Bagg A, Levine BL, June CH, Stadtmauer EA. Chimeric antigen receptor T cells against CD19 for multiple myeloma. N Engl J Med. 2015;373:1040-7.

25. Grada Z, Hegde M, Byrd T, Shaffer DR, Ghazi A, Brawley VS, Corder A, Schonfeld K, Koch J, Dotti G, Heslop HE, Gottschalk S, Wels WS, Baker ML, Ahmed N. TanCAR: a novel bispecific chimeric antigen receptor for Cancer immunotherapy. Mol Ther Nucleic Acids. 2013;2:e105.

\section{Publisher's Note}

Springer Nature remains neutral with regard to jurisdictional claims in published maps and institutional affiliations.

Ready to submit your research? Choose BMC and benefit from:
- fast, convenient online submission
- thorough peer review by experienced researchers in your field
- rapid publication on acceptance
- support for research data, including large and complex data types
- gold Open Access which fosters wider collaboration and increased citations
- maximum visibility for your research: over 100M website views per year
At BMC, research is always in progress.
Learn more biomedcentral.com/submissions

